\title{
A brief background to Rural Restructuring in China: A forthcoming special issue of Journal of Rural Studies
}

\author{
LONG Hualou, LIU Yansui \\ Institute of Geographic Sciences and Natural Resources Research, CAS, Beijing 100101, China
}

Rural China has experienced a rapid and far-reaching transition in the past three or four decades since Deng Xiaoping launched economic reforms in 1978. As China evolves into a majority urban country, these processes present a number of challenges to the rural areas which have been confronted with significant changes and subsequent restructuring of rural socio-economic morphology and territorial spatial patterns, including changes in demographic structures, employment opportunities, community organization, lifestyles and standards of living, accessibility, rural culture as well as the restructuring of rural industries and rural production, living and ecological space (Woods, 2005; Long et al., 2012; Long, 2014).

There are significant spatial variations in the experience and impact of economic and social restructuring in rural China (Li et al., 2015). Whilst rural income levels have improved in many regions, especially those close to large urban centers, urban-rural inequalities in income and uncoordinated urban-rural development have increased in more developed regions (Long et al., 2011; Liu et al., 2013). Yet rural restructuring in China continues to be strongly shaped by national macroeconomic development strategies, a critical analysis of which is needed so as to gain a new recognition of the centrality of rural restructuring to the development of the national economy (Long and Woods, 2011; Long et al., 2012).

Meanwhile, rural China is increasingly integrated into global social and economic networks (Long and Woods, 2011; Woods, 2012). Increased political, economic and cultural openness has exposed rural localities in China to globalization processes - such as global trade and economic competition, international migration, and cultural assimilation - that are already contributing to the reconstitution of rural places elsewhere (Woods, 2007, 2012). As such, the problems associated with rural restructuring in China may in part be addressed by drawing on experiences and achievements from other countries, which may have experienced similar developmental stages as part of their trajectory of rural progression (Long and Woods, 2011).

This Special Issue seeks theoretically rich and diverse papers which engage the contemporary rural restructuring in China, focusing on the processes, responses and experiences in restructuring, and the key challenges for rural areas. The objective of this Special Issue is to disseminate state-of-the-art research results in this research area, to promote further research interests and activities enabling sustainable transformation development in rural China. This Special Issue will be published in August 2016 to coincide with the 33rd International Geographical Congress (IGC) of IGU, to be held in Beijing.

Please feel free to contact the guest editors in advance for advice on potential suitability of any proposed manuscripts. For general guidelines on the appropriate preparation of manuscripts please visit the Journal of Rural Studies website. To ensure that all manuscripts are correctly 
identified for inclusion into the special issue, it is important to select SI: China Rural Restructuring when the authors reach the "Article Type" step in the submission process.

Submission website: http://ees.elsevier.com/rural

Deadline for submission: 31 st October 2015

\section{Guest Editors}

Hualou Long (longhl@igsnrr.ac.cn), Yansui Liu (liuys@igsnrr.ac.cn)

\section{References}

Li Y R, Long H L, Liu Y S, 2015. Spatio-temporal pattern of China's rural development: A rurality index perspective. Journal of Rural Studies, 38: 12-26.

Liu Y S, Lu S S, Chen Y F, 2013. Spatio-temporal change of urban-rural equalized development patterns in China and its driving factors. Journal of Rural Studies, 32: 320-330.

Long H L, 2014. Land consolidation: An indispensable way of spatial restructuring in rural China. Journal of Geographical Sciences 24(2): 211-225.

Long H L, Li Y R, Liu Y S et al., 2012. Accelerated restructuring in rural China fueled by 'increasing vs. decreasing balance' land-use policy for dealing with hollowed villages. Land Use Policy, 29(1): 11-22.

Long H L, Woods M, 2011. Rural restructuring under globalization in eastern coastal China: What can be learned from Wales? Journal of Rural and Community Development, 6(1): 70-94.

Long H L, Zou J, Pykett J et al., 2011. Analysis of rural transformation development in China since the turn of the new millennium. Applied Geography, 31(3): 1094-1105.

Woods M, 2005. Rural Geography: Processes, Responses and Experiences in Rural Restructuring. London: Sage.

Woods M, 2007. Engaging the global countryside: Globalization, hybridity and the reconstitution of rural place. Progress in Human Geography, 31: 485-507.

Woods M, 2012. New directions in rural studies? Journal of Rural Studies, 28(1): 1-4. 